\title{
Is the Merger Necessary? \\ The Interactive Effect of Perceived Necessity and Sense of Continuity on Post-Merger Identification
}

\author{
Steffen R. Giessner
}

\begin{tabular}{|l|l|}
\hline \multicolumn{2}{|l|}{ ERIM REPORT SERIES RESEARCH IN MANAGEMENT } \\
\hline ERIM Report Series reference number & ERS-2011-017-ORG \\
\hline Publication & August 2011 \\
\hline Number of pages & 37 \\
\hline Persistent paper URL & \\
\hline Email address corresponding author & sgiessner@rsm.nl \\
\hline Address & Erasmus Research Institute of Management (ERIM) \\
& RSM Erasmus University / Erasmus School of Economics \\
& Erasmus Universiteit Rotterdam \\
& P.O.Box 1738 \\
& 3000 DR Rotterdam, The Netherlands \\
& Phone: + 31 10 408 1182 \\
& Fax: + 31104089640 \\
& Email: info@erim.eur.nl \\
& Internet: $\quad$ www.erim.eur.nl \\
\hline
\end{tabular}

Bibliographic data and classifications of all the ERIM reports are also available on the ERIM website: www.erim.eur.nl 


\section{ERASMUS RESEARCH INSTITUTE OF MANAGEMENT}

\section{REPORT SERIES}

\section{RESEARCH IN MANAGEMENT}

\begin{tabular}{|l|l|}
\hline ABSTRACT AND KEYWORDS \\
\hline Abstract & $\begin{array}{l}\text { The changes experienced during a merger often reduce post-merger organizational identification } \\
\text { among the workforce, thereby undermining the strategic goals of the merger. While previous } \\
\text { research has shown that employees' post-merger identification suffers less when they } \\
\text { experience a sense of continuity, the current paper explores methods of preserving post-merger } \\
\text { identification even when employees experience a sense of discontinuity. It is hypothesized that } \\
\text { for these employees, the perceived necessity of the merger strongly influences post-merger } \\
\text { identification, because a sense of necessity can reduce the uncertainty that typically inhibits } \\
\text { post-merger identification. A field study is presented (N = 144) to support this hypothesis. Finally, } \\
\text { implications for the organizational pre-merger communication process are discussed. }\end{array}$ \\
\hline Free Keywords & organizational merger, sense of continuity, necessity, post-merger identification, uncertainty \\
\hline Availability & $\begin{array}{l}\text { The ERIM Report Series is distributed through the following platforms: } \\
\text { Academic Repository at Erasmus University (DEAR), DEAR ERIM Series Portal } \\
\text { Social Science Research Network (SSRN), SSRN ERIM Series Webpage } \\
\text { Research Papers in Economics (REPEC), REPEC ERIM Series Webpage }\end{array}$ \\
\hline Classifications & $\begin{array}{l}\text { The electronic versions of the papers in the ERIM report Series contain bibliographic metadata } \\
\text { by the following classification systems: } \\
\text { Library of Congress Classification, (LCC) LCC Webpage } \\
\text { Journal of Economic Literature, (JEL), JEL Webpage } \\
\text { ACM Computing Classification System CCS Webpage } \\
\text { Inspec Classification scheme (ICS), ICS Webpage }\end{array}$ \\
\hline
\end{tabular}




\title{
Running Head: CONTINUITY AND NECESSITY
}

\author{
Is the merger necessary? The interactive effect of perceived necessity and sense of continuity on \\ post-merger identification
}

\section{Steffen R. Giessner}

Rotterdam School of Management, Erasmus University

Published 2011 in Human Relations, 64(8), 1079-1098. doi: 10.1177/0018726711406979

I thank Johannes Ullrich, Stephen Deery, Rolf van Dick and two anonymous reviewers for the constructive feedback on this manuscript. Further, I thank Rashna Kadier for collecting the data. Finally, I thank the Erasmus Trustfonds (Reference: 97095.49/09.0417/evt) for supporting this research. 


\begin{abstract}
The changes experienced during a merger often reduce post-merger organizational identification among the workforce, thereby undermining the strategic goals of the merger. While previous research has shown that employees' post-merger identification suffers less when they experience a sense of continuity, the current paper explores methods of preserving post-merger identification even when employees experience a sense of discontinuity. It is hypothesized that for these employees, the perceived necessity of the merger strongly influences post-merger identification, because a sense of necessity can reduce the uncertainty that typically inhibits post-merger identification. A field study is presented $(N=144)$ to support this hypothesis. Finally, implications for the organizational pre-merger communication process are discussed.
\end{abstract}

KEYWORDS: Organizational Merger; Sense of Continuity; Necessity; Post-merger Identification; Uncertainty 


\section{Is the merger necessary? The interactive effect of perceived necessity and sense of continuity on post-merger identification}

Organizational mergers often decrease employees' identification with and support for the newly merged organization (Blake and Mouton, 1985; Haunschild, Moreland and Murrell, 1994; van Dick, 2004). In turn, a decrease in post-merger identification can result in lower job satisfaction, declining organizational citizenship behavior, lower team performance, and increased turnover intentions (Jetten, O'Brien, and Trindall, 2002; Ullrich and van Dick, 2007; van Dick, Ullrich, and Tissington, 2006; cf. also Rousseau, 1998) - all of which jeopardize the strategic goals of the merging organization. Recent merger research based on Social Identity Theory (Tajfel and Turner, 1986) and Self-Categorization Theory (Turner, Hogg, Oakes, Reicher, and Wetherell, 1987) indicates that a stronger sense of continuity of the pre-merger organizational identity (cf. Rousseau, 1998) inhibits the detrimental effects of a merger on employees' post-merger identification (Giessner, Viki, Otten, Terry, and Täuber, 2006; Jetten et al., 2002; Ullrich, Wieseke, and van Dick, 2005; van Leeuwen, van Knippenberg, and Ellemers, 2003; van Knippenberg, van Knippenberg, Monden, and de Lima, 2002; cf. also Rousseau, 1998). Sense of continuity is a general feeling that the merged organization is a continuation of the pre-merger organization (van Leeuwen et al., 2003; van Knippenberg \& van Leeuwen, 2002; van Knippenberg et al. 2002) and may be influenced by various factors (e.g., structural changes, changes in colleagues, organizational status, etc.). As mergers often involve substantial change, providing a sense of continuity of identity can be difficult. Consequently, it is crucial to understand when and how the detrimental effects of mergers on post-merger identification can be buffered for employees who experience a sense of discontinuity of their pre-merger identity.

The present paper offers insights into this question and makes several new contributions to our understanding of how to increase post-merger identification when employees experience a 
discontinuity of their organizational identity. First, based on social identity perspectives on mergers and acquisitions (Terry, 2001; van Knippenberg et al., 2002; Ullrich and van Dick, 2007) and studies on the consequences of perceiving a necessity behind the merger (Boen, Vanbeselaere, Hollants, and Feys, 2005a; Boen, Vanbeselaere, and Swinnen, 2005b; Ullrich et al., 2005), this paper argues that perceiving the merger as a necessity can decrease perceived uncertainty related to the merger and thus increase employees' post-merger identification, especially for employees who experience a relatively low (vs. high) sense of continuity (i.e., a moderation hypothesis). Second, this paper predicts that the interactive effects of perceived necessity and sense of continuity of identity on post-merger identification are explained via the effects on uncertainty (i.e., a mediated moderation hypothesis). First empirical evidence for this model is provided. This paper focuses mainly on the subjective experiences of employees during a merger. The paper concludes with a discussion of how these findings can be used to improve communication strategies before and during a merger.

\section{Post-merger identification}

Mergers are extreme organizational change processes that can generate high levels of uncertainty (Marks and Mirvis, 2001; Schweiger and DeNisi, 1991) and, therefore, can significantly influence the degree of employees' organizational identification (Amiot, Terry, and Callan, 2007; Giessner et al., 2006; Jetten et al., 2002; Terry, 2001, Ullrich et al., 2005). Organizational identity has been defined in different ways and from different theoretical perspectives (for an overview, see Haslam, Postmes, and Ellemers, 2003). In this paper, it is defined as a "relatively enduring state that reflects an individual's willingness to define him- or herself as a member of a particular organization" (p. 382, Haslam, 2001). This definition of organizational identification is grounded in the social identity approach (Tajfel and Turner, 1986; Turner et al., 1987). The basic assumption of this approach is that people define themselves not 
only on the basis of their individual characteristics and interpersonal relations (i.e., personal identity), but also in terms of the characteristics of the groups to which they belong (i.e., social identity). In other words, social groups can form a significant part of one's self-concept through the process of self-stereotyping (i.e., internalization of the organization's defining characteristics, norms and values). In turn, these internalized norms, values, and characteristics gleaned from the organization can significantly influence the thoughts, actions, and feelings of its members (see Haslam et al., 2003). Thus, organizational identification often forms an important part of the selfconcept of an employee (Ashforth and Mael, 1989; Hogg and Terry, 1999).

A common problem with organizational mergers is that they cause employees to feel uncertain about the organization's future (DiFonzo and Bordia, 1998; Marks and Mirvis, 2001; Schweiger and DeNisi, 1991). Such feelings of uncertainty motivate individuals to identify with other groups to reduce their anxiety (Hogg, 2007). Unfortunately, this uncertainty often results in strong levels of identification with the pre-merger organization instead of the post-merger organization (Gleibs, Mummendey, and Noack, 2008; Haunschild et al., 1994; Terry, 2001). This phenomenon is problematic because low levels of post-merger identification disrupt the integration process (Cartwright, 2005; Haslam, 2001; Terry, 2001). Post-merger identification is positively related to job satisfaction, organizational citizenship behavior, emotional well-being, team performance, and reduced turnover intentions (Jetten et al., 2002; Lipponen, Olkkonen, and Moilanen, 2004; Olkkonen and Lipponen, 2006; Terry, Callan, and Carey, 2001; van Dick et al., 2006; van Dick, Wagner and Lemmer, 2004). All these considerations combine to overwhelmingly indicate that post-merger identification is an important precursor of success on the human side of the merger process.

\section{Sense of continuity and post-merger identification}


But under what conditions do employees identify with the post-merger organization and how can the uncertainty of the merger be overcome to facilitate post-merger identification? These questions have been addressed in recent years by several researchers. The study of post-merger identification has explicitly focused on change and continuity as factors affecting organizational identification. Rousseau (1998), for instance, argues that change per se is not the most important factor influencing organizational identification. Indeed, employees know that organizations have to change from time to time. However, despite organizational changes, employees generally want to feel that they continue working for the same organization (Jetten et al., 2002; van Knippenberg et al., 2002). Rousseau (1998) termed this feeling a "sense of continuity" and argued that this sense of continuity is essential if employees are to maintain their identification with the organization in the wake of major organizational changes. As organizational identification gives meaning to one's self definition (Haslam, 2004; Ashforth \& Mael, 1989), a sense of continuity should reduce self-uncertainties during organizational changes. If, however, employees experience a decrease in the sense of continuity of their organizational identity, they are likely to feel uncertain about their future situation (Jetten et al., 2002; Marks and Mirvis, 2001; Schweiger and DeNisi, 1991) and, as a result, to identify less with the organization (Giessner et al., 2006; Jetten et al., 2002).

Although various events can alter employees' sense of continuity, these events typically involve identity-defining characteristics (van Dick et al., 2006; van Leeuwen et al., 2003; van Knippenberg et al., 2002), such as the name of the organization, corporate design, organizational goals, organizational culture and organizational structure (Giessner et al., 2006). However, continuous organizational changes are less prone to alter sense of continuity compared to radical organizational changes (Ullrich et al., 2005). An organizational merger is among the most dramatic organizational changes employees can experience (Hogan and Overmyer-Day, 1994). 
Based on Rousseau's (1998) concept of sense of continuity and on the social identity perspective (Tajfel and Turner, 1986; Turner et al, 1987; see also Ashforth and Mael, 1989), van Knippenberg and colleagues (2002) argue that the sense of continuity of the organizational identity is key to understanding when and why employees identify with post-merger organizations. They demonstrate that the stronger an employee's sense of continuity, the more that employee tends to identify with the post-merger organization. In other words, employees who feel the merged organization is still their organization tend to identify with the merged organization (see also Jetten et al., 2002). In contrast, employees who perceive little relation between their former organization and the merged organization tend to experience lower levels of post-merger identification. This relationship has been repeatedly demonstrated in field studies (Boen et al., 2005a, 2005b; Jetten et al., 2002; van Knippenberg, et al., 2002) and experiments (van Leeuwen et al., 2003; see also Boen, Vanbeselaere, Brebels, Huybens, and Millet, 2007; Boen, Vanbeselaere, and Wostyn, 2010; Giessner et al., 2006).

\section{Necessity and post-merger identification}

Although past research on sense of continuity has proven valuable to theory and practice, it does not yet suggest what can be done to salvage post-merger identification among employees who experience a discontinuity of their organizational identity? Employees who experience a discontinuity of their organizational identity tend to experience higher levels of uncertainty, which hinders identification with the post-merger organization (cf. Ullrich et al., 2005). Given that organizational mergers generally imply dramatic changes for at least one of the merging partners (most often for employees of the low status organization, van Knippenberg et al., 2002, but see Giessner et al., 2006 for cases in which high status organization experience dramatic changes), it is important to determine what factors might positively influence the degree of postmerger identification among the employees most impacted by the merger. 
Merger decisions by top management are most often undertaken to help the organization (Cartwright and Cooper, 1996). Unfortunately, the necessity of a merger is not always clear to the employees of the merging organizations. A merger's perceived necessity is defined as employees' perception of the merger as motivated by the managerial and strategic aims of growth and/or survival of the organization (Boen et al, 2005a, 2005b). Given the potentially dramatic changes employees experience during a merger, understanding that the merger is necessary might help employees to cope with their loss of identity and the related feelings of uncertainty. According to the social identity perspective, individuals are motivated to identify with a group (e.g., postmerger organization) because of the motivation to self-enhance and to reduce uncertainty (Hogg, 2007; Tajfel and Turner, 1986). Prior research has shown that uncertainty can be reduced through giving meaning to a social situation (Hogg, 2007). By providing a clear picture of the common fate of the organizations, the merger process receives meaning. This paper argues that employees' understanding of the reasons and goals behind the merger should clarify the organization's future identity (Ullrich et al., 2005) and increase the belief in a common fate for all employees involved in the merger process (Hogg, 2007). Conversely, confusion about the future of the organization creates frustration and uncertainty which, in turn, increases the need to self enhance and the need to reduce uncertainty (Ullrich et al., 2005). Consequently, perceiving the merger as necessary should reduce uncertainty and help employees to make sense of the new organizational identity. Other factors besides perceived necessity may influence employees' feelings of uncertainty surrounding a merger. However, perceived necessity might be able to reduce identity-related feelings of uncertainty due to a merger (cf. Hogg, 2007). Indeed, previous research has shown that perceived necessity of the merger positively influences post-merger identification (Boen et al., 2005a, 2005b; Ullrich et al., 2005). However, the research to date has neither explained the 
underlying the process that mediates this influence nor identified the subset of employees for whom necessity perceptions matter the most.

\section{Sense of continuity, motivation and post-merger identification}

Extending previous research, this paper argues that the perceived necessity of a merger affects the post-merger identification of employees who experience a discontinuity of organizational identity to a greater degree than those who experience a greater sense of continuity. Employees with a strong sense of continuity of identity tend to report neither the experience of dramatic organizational change nor the associated feelings of threat and uncertainty (Rousseau, 1998). Their identity subjectively remains intact and, therefore, they tend not to feel uncertain about their positions within the merged organization (Hogg, 2007). These employees tend to identify more strongly with the post-merger organization than employees who experience a discontinuity of organizational identity (Ullrich et al., 2005; van Leeuwen et al., 2003; van Knippenberg et al., 2002). Consequently, for these employees, information about the necessity of the merger likely has relatively little impact on their feelings of uncertainty or their post-merger identification.

In contrast, employees with a low sense of continuity tend to feel uncertain about the merger and to question their organizational identities (Jetten et al., 2002; Ullrich et al., 2005). These employees tend to be uncertain about their place within the merged company and what the new organization stands for. In line with the uncertainty reduction hypothesis of the social identity perspective (Hogg, 2007), this paper argues that understanding the necessity of the merger in terms of its underlying motives can reduce uncertainty related to the organizational merger by helping these employees to justify the changes and adjust to a new meaning for the organizational identity (cf. Hogg, 2007). Thus, although the identity of the old organization might be lost (i.e., low sense of continuity), employees who accept the necessity of the merger tend to 
understand the goals and direction of the merged organization, reducing identity-related uncertainties about the merger and thus increasing post-merger identification. These arguments yield the following hypotheses:

Hypothesis 1 . The positive relationship between perceived necessity and post-merger identification is stronger when employees experience a low (vs. high) sense of continuity of their organizational identities during a merger. In other words, a sense of continuity negatively moderates the positive relationship between perceived necessity of the merger and post-merger identification. (i.e. moderation hypothesis).

Hypothesis 2. The negative relationship between perceived necessity and uncertainty is stronger when employees experience a low (vs. high) sense of continuity of their organizational identities during a merger. In other words, a sense of continuity negatively moderates the negative relationship between perceived necessity of the merger and uncertainty (i.e. moderation hypothesis).

Hypothesis 3. The moderation predicted in hypothesis 2 explains the moderation predicted in hypothesis 1 . In other words, uncertainty mediates the interactive effect of sense of continuity and perceived necessity on post-merger identification (i.e., mediated moderation hypothesis). This hypothesis is also presented in Figure 1.

INSERT FIGURE 1 ABOUT HERE

Study

The study was conducted as a field study in the context of merging water control board organizations in the Netherlands. These public organizations ensure the successful management of water in the Netherlands. Thus, their main tasks are the maintenance of dikes and water quality. In 1950, there were 2,500 water control board organizations throughout the country. This 
number decreased radically through merging to only 27 organizations by 2005 . The current study was conducted during a merger of four water control board organizations in 2005 , creating a single merged organization. Within this merger, one organization clearly enjoyed the highest status and had the highest number of employees (about 400). The merged organization assumed the name of the dominant organization as well as most features of its organizational structure and culture. The other three water control board organizations were smaller in size (varying from about 130 to about 50) and had to adapt to align with the high-status organization.

\section{Method}

Participants and Procedure. Questionnaires were distributed to the employees of the merged water control board organization six months after the merger took place. In cooperation with this organization, it was possible to distribute questionnaires randomly to 150 employees working in the head office. The number of participants was restricted by the organization. At the time, approximately 450 employees worked at the headquarters and the organization included 700 employees overall. Only employees who experienced the merger in 2005 took part.

Among the 150 employees, 144 respondents filled in the questionnaire, and four incomplete questionnaires were discarded. The response rate was $93 \%$, and most of the respondents were male $(\mathrm{N}=106)$. The age of the respondents varied from 21 to 65 years $(\mathrm{M}=$ 42.55, $\mathrm{SD}=9.83)$. The sample's gender distribution ( $76 \%$ male, $24 \%$ female) corresponds closely with the overall gender distribution of the organization ( $77 \%$ male, $23 \%$ female $), \chi^{2}=$ $.02, p=n . s$. In addition, the average age of the sample nearly matched the overall average age of employees at the organization (42 years). However, due to missing information about the variation of age in the organization, it was not possible to test statistically for representativeness of the sample. In terms of representation of the pre-merger organization, $31 \%$ of respondents 
came from the high-status organization, and the percentages of the employees from the lowerstatus pre-merger organizations varied between $35 \%$ and 13\%. Although this distribution does not match the proportions of the merged organizations, it represents a relatively large sample to test the predictions.

Measures. All items are provided in the Appendix. Table 1 summarizes all means, standard deviations, internal consistency and correlations of the measures used. Participants answered questions on 5-point scales ranging from 1 (= strongly disagree) to 5 (= strongly agree). To measure perceived necessity of the merger, the study employed a short measure adapted from Boen and colleagues (2005a, 2005b). Participants indicated the extent to which they perceived the merger as necessary in terms of both a survival motive and a growth motive. The two items correlated significantly, $r(138)=.43, p<.001$ and preliminary analyses indicated that both items produced very similar effects. Therefore, an average score was used as a measure of perceived necessity of the merger. Next, participants answered a 3-item scale measuring sense of continuity adapted from van Leeuwen et al. (2003). The scale was reliable. A 3-item scale adapted from van Knippenberg et al. (2002) to measure post-merger identification was also included. Additionally, participants filled out a 4-item scale measuring uncertainty related to the merger (adapted from Giessner et al., 2006, and Schweiger and DeNisi, 1991). Finally, participants provided demographic information: gender, age, pre-merger organization, and years of employment at the pre-merger organization.

\section{INSERT TABLE 1 ABOUT HERE}

\section{Results}

CFA of measured constructs. A confirmatory factor analysis was performed to examine the distinctiveness of the study's scales (using LISREL 8.80). A four-factor model was specified 
presenting the latent variables necessity, sense of continuity, uncertainty, and post-merger identification. The expected four-factor model fitted the data well, $\chi^{2}(48)=76.99, p=.005$, NFI $=.92, \mathrm{CFI}=.96, \mathrm{GFI}=.92, \mathrm{SRMR}=.069$ (see Kline, 1998). $\mathrm{A}$ chi-square difference test indicated that the four-factor model yielded a better fit to the data than did any of the one-factor models, $\Delta \chi^{2}(6)=230.08, p<.001$, or any conceivable two- or three-factor model. In addition, tests of all pairs of subscales (e.g., post-merger identification and sense of continuity) yielded a better fitting two-factor solution compared to a one-factor solution.

Post-Merger Identification. A hierarchical regression analysis on post-merger identification was conducted (see Table 2), using centered variables in all regression analyses (Aiken \& West, 1991). The original organization of the respondents was included in the first step of the analyses as a dummy-coded variable to control for potential effects of the participants' pre-merger organizational membership ${ }^{1}$. In the second step, the main effects of perceived continuity and necessity were included. Finally, in the third step, the interaction term was included.

The first step explained a significant portion of the variance in post-merger identification, indicating that the pre-merger organizational membership influenced the degree to which the participants identified with the post-merger organization ${ }^{2}$. The second step of the analysis yielded significant positive relationships with post-merger identification for both perceived continuity and necessity. More importantly, the interaction of continuity and necessity was significant in the third step. Following Aiken and West (1991), the study tested for the simple slopes of this interaction (see Figure 2). As predicted, the perceived necessity of the merger had a strong positive relationship to post-merger identification when perceptions of continuity were low, $b=$ $.26, S E b=.07$, beta $=.32 ; p=.001$. In contrast, when perceived sense of continuity was high, necessity did not significantly predict post-merger identification, $b=.02$, SE $b=.09$, beta $=.02 p$ $=.87$. 
Because the relative statuses of the pre-merger organizations could potentially influence the predicted relationship, a second hierarchical regression analysis was conducted with status of the pre-merger organization $(0=$ low, $1=$ high), sense of continuity and necessity (see Table 3$)$. The first step included the main effects, the second step included all two-way interactions, and the third step included the three-way interaction. As in the first regression, only necessity and sense of continuity significantly related to post-merger identification in step 1 . Further, the interaction of sense of continuity and necessity again was significant in step 2 . All other effects were non-significant. This analysis indicates that the status of the pre-merger organizations does not change the relationship found in the first regression analysis.

Uncertainty. The same hierarchical regression analyses were also conducted on the measure of uncertainty. The first step explained a significant portion of the variance in perceived uncertainty, indicating that organizational background influenced the level of uncertainty ${ }^{3}$. The second step yielded a significant effect on uncertainty. In this case, only perceived continuity negatively related to uncertainty. More importantly, however, the interaction of perceived necessity and continuity was significant in the third step. Following Aiken and West (1991), the study tested for the simple slopes of this interaction (see Figure 2). Although these simple slopes did not reach the commonly accepted level of significance, the pattern of the slopes supports hypothesis 2 . Necessity correlated negatively with uncertainty when perceptions of continuity were low, $b=-.12$, SE $b=.08$, beta $=-.13, p=.18$. In contrast, when perceived sense of continuity was high, necessity correlated positively with uncertainty, $b=.16, S E b=.11$, beta $=$ $.19, p=.15$.

Again, a second hierarchical regression analysis was conducted with status as the independent variable (see Table 3). As with the similar analysis relating to post-merger 
identification, this analysis yielded no significant effect of status or its interactive effects. Rather, the interaction of necessity and sense of continuity was again significant.

\section{INSERT TABLE 2, 3, 4, 5 AND FIGURE 2 ABOUT HERE}

Mediation Analysis. Mediated moderation was tested by using the procedures for moderated regression analysis and path analysis recommended by Edwards and Lambert (2007). This method provides a precise testing of hypothesis 3. Edwards and Lambert (2007) frame mediation as a path model; relationships among variables are expressed with regression equations and tested via bootstrapping methods (Efron and Tibshirani. 1993). Moderation is incorporated by supplementing these equations with the moderator variable and its product with the independent variable (Baron and Kenny, 1986). The equations are integrated through reducedform equations by substituting the regression equation for the mediator variable into the equation for the dependent variable. This approach produces tests for direct, indirect, and total effects for different values of the moderator variable. It offers the advantage of directly testing the specified mediated model and provides statistical tests of moderation for the specific path (Edwards and Lambert, 2007). As hypothesis 3 corresponds to a 'First Stage Moderation Model', the study followed the steps suggested by Edwards and Lambert (2007) to test for this model. All analyses controlled for organizational membership of the participants (as in the first regression analyses on post-merger identification and uncertainty). Table 3 reports the results of the regression analyses. Table 4 reports simple effects for each path of the mediated model, as well as the indirect and total effects.

For uncertainty, the regression analyses reported in Table 3 indicate that sense of continuity moderated the path from perceived necessity to uncertainty. The coefficients in Table 3 were used to calculate the simple effects reported in Table 4. As predicted, for low sense of continuity 
(i.e., one standard deviation below the mean), necessity significantly (i.e., one-sided testing) decreased uncertainty (first stage) which in turn significantly increased post merger identification (second stage). The complete indirect mediation path (indirect effect) is significant in the predicted direction (i.e., one-sided testing) as well. In contrast, for high sense of continuity (i.e., one standard deviation above the mean), there was no longer a significant relationship between necessity and uncertainty and also no significant indirect mediation path. More importantly, the difference in the indirect mediation is significant, reflecting a significant difference of the indirect mediation path between low and high continuity, which supports hypothesis 3 . Furthermore, the total effect is significantly stronger for the low (vs. high) continuity condition. Taken together, the results of this analysis yield strong support for hypothesis 3, suggesting that indeed perceived necessity becomes a more important predictor of post-merger identification via uncertainty for employees experiencing low (vs. high) sense of continuity.

\section{Discussion}

The field study results presented above integrate and extend organizational merger research on the social identity perspective on post-merger identification (Giessner et al., 2006; Gleibs et al., 2008; Terry, 2001; Ullrich et al., 2005; van Knippenberg et al., 2002). While former research in this tradition focused on the sense of continuity of the organizational identity to explain post-merger identification (cf. Rousseau, 1998), the current research extends this perspective by providing theoretical and empirical evidence for an interaction between sense of continuity and perceived necessity in predicting post-merger identification. This study suggests that perceived necessity of the merger predicts post-merger identification especially for employees who experience a low (vs. high) sense of continuity of identity. This finding is of theoretical and practical importance because most organizational mergers involve dramatic 
changes, resulting in a low sense of continuity of identity for members of at least one of the merging organizations (Cartwright and Cooper, 1996, Hogan and Overmyer-Day, 1994).

\section{Continuity of Organizational Identity}

The current findings have important theoretical implications for the study of continuity of organizational identity. Previous research suggests that any uncertainty about the new organizational identity elicits resistance and thus a decrease in post-merger identification (Giessner et al., 2006; Schweiger and DeNisi, 1991; Terry, 2001; Ullrich et al., 2005). In turn, van Knippenberg and colleagues (2002) proposed that a sense of continuity of the pre-merger identity increases post-merger organizational identification (see also Jetten et al., 2002; Rousseau, 1998). In line with this prediction, previous research has mainly concentrated on how the sense of continuity can be strengthened to elicit stronger post-merger identification. However, mergers usually represent dramatic organizational change for some employees of the merging organizations. As such, many employees are likely to experience a low sense of continuity or strong ambiguity about their future organizational identity (Terry, 2001). The current findings suggest that understanding the necessity of the merger can help employees to reconstruct a strong sense of organizational identity after experiencing a discontinuity of their previous organizational identity.

Typically, the members of the lower status organization(s) experience a relatively low sense of continuity (van Knippenberg et al., 2002). However, members of low-status and highstatus organizations have different expectations regarding the sense of continuity they will experience due to a merger. Giessner and colleagues (2006) showed in a series of studies that the members of the high-status organization expect assimilation or an integration in which their original organization is strongly represented in the post-merger organization (i.e., strong sense of continuity). However, they did not respond well to an equal representation in the merged 
organization (i.e., a relatively lower degree of sense of continuity). In contrast, employees of the low-status organization tend to strongly support an equal representation in the merger. In other words, high-status and low-status organizations differ in their baseline expectations about sense of continuity and it is these different expectations that matter in determining organizational identification outcomes. This previous research aligns with the current findings, in which sense of continuity (controlling for employees' pre-merger organizational membership) rather than status of organizational membership interacts with perceived necessity in the prediction of postmerger identification.

The current findings also have some parallels to the research on projected sense of continuity (Ullrich et al., 2005). Ullrich and colleagues argue that sense of continuity might be a positive-sum game between the dominant and dominated merger partners. Based on a qualitative case study of an organizational merger, they suggest that there are two different types of continuity: observable and projected. The former type relates to the sense of continuity as used in this research, while the latter type reflects a "subjective belief that the relationship between path and goal is clear and controllable" (p.1562). In this sense, projected continuity reflects a clear goal of the merger and a clear idea of how to reach this goal. This projected sense of continuity might also be able to increase post-merger identification. Indeed, this conception of the projected sense of continuity seems closely related to the necessity of the merger. However, the current research extends Ullrich's et. al.'s model of dual continuity (observable and projected) by showing that the relationship between perceived necessity, which resembles projected continuity, and post-merger identification is contingent on the observable sense of continuity of identity.

Similarly, Boen and colleagues (2005a, 2005b) empirically demonstrated that perceived necessity is a predictor of post-merger identification. Importantly, however, the current research extends these findings by providing first empirical evidence of the interactive effects between 
perceived necessity and sense of continuity on post-merger identification. In addition, the current results provide evidence for the underlying mechanism of uncertainty reduction related to the merger. In this way, the present results both corroborate and extend former research on perceived necessity and projected sense of continuity.

\section{Implications for Merger Practice}

The current findings point to several considerations germane to the practitioner. Most importantly, these findings highlight the importance of strong internal communication before and during a merger. If managers can convince their employees that the organization will remain relatively unchanged or that the merger is necessary for the organization as a whole, the employees are far more likely to identify with the merged organization, thus minimizing problems related to the human factors of the merger. However, it might be difficult to influence such employee perceptions, because employees who experience change tend to rely on a wide variety of resources in their sense-making process (cf. Rousseau and Tijoriwala, 1999). Thus, even if the internal communication process focuses on these important topics, employees might gather diverging information from other sources (e.g., through gossip, external media, etc.). Therefore, one promising strategy might be to monitor the uncertainties of the employees at the beginning of the integration process and to communicate more clearly the necessity of the merger towards the employees with high uncertainty. Such a proactive strategy could prevent a vicious circle in which uncertainties related to the merger increase over time and end up hindering post merger identification.

In addition to human resource practitioners, executives planning mergers might also glean lessons from these findings. Sometimes mergers simply lack legitimacy (e.g., hostile takeovers). Furthermore, a merger might be based primarily on egoistical motives of the management (Cartwright \& Cooper, 1996). If employees perceive such self-serving motives of the 
management, they are less likely to support organizational changes (Rousseau \& Tijoriwala, 1999). In such cases, management has to find ways to communicate the underlying motive of the merger as growth or survival. Otherwise, it is rather unrealistic to convince employees of the necessity of the merger, and executives should take into consideration the higher costs involved in the merger integration phase. Perhaps only such organization-wide motives as growth and survival can elicit feelings of necessity among rank and file employees. This line of inquiry could prove fertile ground for future research.

Legitimacy can also pose problems for a management team trying to convince employees of a merger's necessity. Previous research has shown that persuasion attempts by outgroup members are less successful than persuasion attempts by ingroup members, because outgroup members are perceived as less trustworthy sources of information (McGarty, Haslam, Hutchinson, and Turner, 1994). A management team can be perceived as an outgroup for two primary reasons. First, if one merger partner takes the lead in the new merged organization, the management team of this organization might be perceived as an outgroup by the members of the other organization(s) involved in the merger. This scenario is very likely, as organizational mergers often heighten the salience of pre-merger group memberships (Giessner and Mummendey, 2008; Terry, 2001). Thus, the management team can be perceived as an outgroup in the sense that they come from the other organization. Second, employees might perceive their own management team as an outgroup - a group who differs from the rank-and-file employees. In both cases, the persuasion attempt might fail because the employees distrust the management team. Thus, employees within each pre-merger organization might require justification of the necessity of the merger via persons perceived as 'one of us' instead of as 'one of them', and these persons might need to come from the rank-and-file workforce rather than from the executive management team. 
The current findings also indicate that feelings of discontinuity of identity are not confined to employees of low-status organizations. Rather, sense of continuity varies within dominant organizations as well. In addition, dominant and submissive organizations tend to have different standards on which they evaluate the subjective sense of continuity. Members of highstatus organizations tend to expect more continuity than members of the low-status organizations (Giessner et al., 2006). Therefore, it is important for all organizations involved in the merger to proactively communicate the necessity of the merger to employees.

\section{Limitations}

The present research, like any other, is not without its limitations. First, although the sample of the study was representative in terms of its gender distribution, it was not possible to test for the representativeness in terms of age. Furthermore, members of the high-status organization were underrepresented in the study. However, the descriptive information available suggest that age composition might be representative and the sample size of the high-status and low-status organizations involved in the merger was large enough to test the hypotheses.

Second, although the current study provides field data supporting the results, measured independent and dependent variables are from the same source. This could create common method variance and thus artificially increase correlations between the variables in focus (Podsakoff, MacKenzie, Podsakoff, and Lee, 2003). However, the focus in this research was on the effect of the interaction between sense of continuity and perceived necessity on post-merger identification. Common method variance makes it less likely to find such an interaction effect (McClelland and Judd, 1993) and cannot explain or artificially create interactions (Evans, 1985).

Furthermore, causality cannot be tested with the current data. However, it is impractical to test real merger processes within a laboratory setting. But the causal data available on the influence of sense of continuity on post-merger identification (Boen et al., 2007, 2010; van 
Leeuwen et al., 2003) seem to support at least a causal linkage between sense of continuity and post-merger identification. In addition, the research cross-sectional design does not allow to draw conclusions on the changes in time. However, a recent studies indicate that time influences the effect of sense of continuity (Gleibs et al., 2008), indicating that the effects of sense of continuity on post-merger identification might become less strong at later merger stages. However, to date no theoretical account has yet addressed this issue in detail.

The current research is based on a social identity approach to organizational mergers (cf. Terry, 2001; Ullrich and van Dick, 2007) and focuses on how post-merger identification can be increased for employees who experience a relatively low sense of continuity. Therefore, this research does not address other factors that might influence post-merger identification and uncertainty.

Another limitation relates to the rather weak effects of the individual variables on uncertainty. First, although the interactive effect of sense of continuity and perceived necessity on uncertainty is significant, the simple slopes did not reach significance. Second, the mediation test yielded significant effects for the first stage and the indirect effect using only one-way significance tests. However, the interaction proves the moderation, and the simple slopes support its direction (Aiken and West, 1991; Dawson and Richter, 2006). Moreover, the mediation tests are in the predicted direction and thus allow for one-way testing (Howell, 1997). Therefore, the results generally support the hypotheses. Still, it might be that the study's measure of uncertainty focused too much on job-related uncertainty, neglecting other aspects of uncertainty. Indeed, previous research (Bordia et al., 2004) suggests that uncertainty involves three inter-related factors: strategic uncertainty, structural uncertainty, and job-related uncertainty. This framework, however, has not yet been applied to a social identity perspective. Such a differentiation of uncertainty might be helpful, and future research could explore whether all three aspects of 
uncertainty are influenced by sense of continuity and perceived necessity or whether only certain aspects of uncertainty are affected.

Finally, the measures used in the study restrict the current scope of generalization. It might be questioned whether each measure used in the study reflects the best possible operationalization of the underlying construct. However, only adapted established measures were used in the study and a confirmatory factor analysis proved that the measures represent distinct constructs.

\section{Conclusion}

Organizational identity is an important aspect of employees' self-concepts (Ashforth and Mael, 1989; Haslam et al., 2003; van Dick, 2004). Organizational mergers often challenge these organizational identities, creating uncertainty and resistance in the workforce and decreasing identification with the merged organization. Organizations, however, must change periodically to compete with other organizations. An organizational merger is a particularly potent form of change with the potential to create strong competitive advantages. While past research has argued that the best way to manage an organizational merger is to provide employees with a feeling of continuity rather than of change (Ullrich et al., 2005; van Knippenberg et al., 2002; van Leeuwen et al., 2003; cf. Rousseau, 1998), the disruptive nature of mergers often makes this strategy impractical. The present research illuminates a new strategy: by effectively communicating the necessity of the merger, executives can avoid merger-induced morale issues despite employees experiencing significant changes to their organizational identities. 


\section{References}

Aiken LS and West SG (1991) Multiple regression: testing and interpreting interactions. Newbury Park, CA.: Sage.

Amiot CE, Terry DJ and Callan VJ (2007) Status, equity and social identification during an intergroup merger: A longitudinal study. British Journal of Social Psychology 46(3): 557-577. Ashforth BE and Mael FA (1989) Social identity theory and the organization. Academy of Management Review 14(1): 20-39.

Baron RM and Kenny DA (1986) The moderator-mediator variable distinction in social psychological research: Conceptual, strategic, and statistical considerations. Journal of Personality and Social Psychology 51(6): 1173-1182.

Blake RR and Mouton JS (1985) How to achieve integration on the human side of the merger. Organizational Dynamics, 13(3): 20-39.

Boen F, Vanbeselaere N, Brebels L, Huybens W and Millet K (2007) Post-merger identification as a function of pre-merger identification, relative representation and pre-merger status.

European Journal of Social Psychology, 37(2): 380-389.

Boen F, Vanbeselaere N, Hollants, K and Feys J (2005a) Predictors of pupils' and teachers' identification with a merged school. Journal of Applied Social Psychology, 35(12): 2577-2605. Boen F, Vanbeselaere N and Swinnen H (2005b) Predicting fans' support for a merged soccer team: A social-psychological perspective. International Journal of Sport Psychology, 36(1): 6585.

Boen F, Vanbeselaere N and Wostyn P (2010) When the best become the rest: The interactive effect of premerger status and relative representation on postmerger identification and ingroup bias. Group Processes and Intergroup Relations, 13(6): 461-475. 
Cartwright S (2005) Mergers and acqusitions: An update and appraisal. In: Hodgkinson GP and Ford JK (eds), International review of industrial and organizational psychology 20. Chichester, UK: Wiley, 1-38.

Cartwright S and Cooper CL (1996) Managing Mergers Acquisitions and Strategic Alliances: Integrating People and Cultures. Oxford: Butterworth-Heinemann.

Dawson JF and Richter AW (2006) Probing three-way interactions in moderated multiple regression: Development and application of a slope difference test. Journal of Applied Psychology, 91(4), 917-926.

DiFonzo N and Bordia P (1998) A tale of two corporations: Managing uncertainty during organizational change. Human Resource Management, 37(3-4): 295-303.

Edwards JR and Lambert LS (2007) Methods for integrating moderation and mediation: A general analytical framework using moderated path analysis. Psychological Methods, 12(1): 1-22. Efron B and Tibishirani RJ (1993) An introduction to the bootstrap. Boca Raton, FL: Chapman and Hall.

Evans MG (1985) A Monte Carlo study of the effects of correlated method variance in moderated multiple regression analysis. Organizational Behavior and Human Decision Processes, 36(3): 305-323.

Giessner SR and Mummendey A (2008) United we win, divided we fail? Effects of cognitive representations and performance feedbacks on merging groups. European Journal of Social Psychology, 32(3), 412-435.

Giessner SR, Viki GT, Otten S, Terry DJ and Täuber S (2006) The challenge of merging: Merger patterns, premerger status, and merger support. Personality and Social Psychology Bulletin, 32(3): 339-352. 
Gleibs I, Mummendey A and Noack P (2008) Predictors of change in post-merger identification throughout a merger process: A longitudinal study. Journal of Personality and Social Psychology, 95(5): 1095-1112.

Haslam SA (2001) Psychology in organisations: The social identity approach. London: Sage. Haslam SA, Postmes T and Ellemers N (2003) More than a metaphor: Organizational identity makes organizational life possible. British Journal of Management, 14(4): 357-369.

Haunschild PR, Moreland RL and Murell AJ (1994) Sources of resistance to mergers between groups. Journal of Applied Social Psychology, 24(13): 1150-1178.

Hogan EA and Overmyer-Day L (1994) The psychology of mergers and acquisitions. In: Cooper CL and Robertson LT (eds), International review of industrial and organizational psychology 9 , Chichester: Wiley, 247-281.

Hogg MA (2007) Uncertainty-identity theory. In: Zanna MP (ed.), Advances in Experimental Social Psychology 39, San Diego: Academic Press, 69-126.

Hogg, MA and Terry DJ (2000) Social identity and self-categorization processes in organizational contexts. Academy of Management Review, 25(1): 121-140.

Howell, DC (1997) Statistical methods for psychology. London : Duxbury Press. Jetten J, O'Brien A and Trindall N (2002) Changing identity: Predicting adjustment to organizational restructure as a function of subgroup and superordinate identification. British Journal of Social Psychology, 41(2): 281-297.

Kline RB (1998) Principles and practice of structural equation modeling. NY: Guilford Press. Lipponen J, Olkkonen ME and Moilanen M (2004) Perceived procedural justice and employee responses to an organizational merger. European Journal of Work and Organizational Psychology, 13(3): 391-413. 
Marks ML and Mirvis PH (2001) Making mergers and acquisitions work: Strategic and psychological preparation. Academy of Management Executive, 15: 80-94.

McClelland GH and Judd CM (1993) Statistical difficulties of detecting interactions and moderator effects. Psychological Bulletin, 114(2): 376-390.

McGarty C, Haslam SA, Hutchinson KJ and Turner JC (1994) The effects of salient group memberships on persuasion. Small Group Research, 25(2): 267-293.

Olkkonen ME and Lipponen J (2006) Relationships between organizational justice, identification with organization and work unit, and group-related outcomes. Organizational Behavior and Human Decision Processes, 100(2): 202-215.

Podsakoff PM, MacKenzie SB, Lee J and Podsakoff NP (2003) Common method biases in behavioral research: A critical review of the literature and recommended remedies. Journal of Applied Psychology, 88(5): 879-903.

Rousseau DM (1998) Why workers still identify with organizations. Journal of Organizational Behavior, 19(3): 217-233.

Rousseau DM and Tijoriwala SA (1999) What's a good reason to change? Motivated reasoning and social accounts in promoting organizational change. Journal of Applied Psychology, 84(4): 514-528.

Schweiger DM and DeNisi AS (1991) Communication with employees following a merger: A longitudinal field experiment. Academy of Management Journal, 34(1): 110-135.

Tajfel H and Turner JC (1986) The social identity theory of intergroup behaviour. In: Worchel S and Austin WG (eds.) Psychology of intergroup relations. Chicago: Nelson-Hall, 7-24. Terry DJ (2001) Intergroup relations and organizational mergers. In Hogg MA and Terry DJ (eds.) Social identity processes in organizational contexts. Philadelphia, PA: Psychology Press, 229-247. 
Terry DJ, Callan VJ and Carey CJ (2001) Employee adjustment to an organizational merger: An intergroup perspective. Personality and Social Psychology Bulletin, 27(3): 267-280.

Turner JC, Hogg MA, Oakes PJ, Reicher SD and Wetherell MS (1987) Rediscovering the social group: A self-categorization theory. Oxford, U.K.: Basil Blackwell.

Ullrich J and van Dick R (2007) The group psychology of mergers and acquisitions: Lessons from the Social Identity Approach. In: Cooper CL and Finkelstein S (eds.) Advances in Mergers and Acquisitions 6. Greenwich, CT: JAI Press, 1-15.

Ullrich J, Wieseke J and van Dick R (2005) Continuity and change in mergers and acquisitions: A social identity case study of a German industrial merger. Journal of Management Studies, 42(8): 1549-1569.

van Dick R (2004) My job is my castle: Identification in organizational contexts. In: Cooper CL, and Robertson IT (eds.) International Review of Industrial and Organizational Psychology 19. Chichester: Wiley, 171-203.

van Dick R, Ullrich J and Tissington PA (2006) Working under a black cloud: How to sustain organizational identification after a merger. British Journal of Management, 17(S1): 69-79. van Dick R, Wagner U and Lemmer G ( 2004) The winds of change. multiple identifications in the case of organizational mergers. European Journal of Work and Organizational Psychology, 13(2): $121-38$.

van Knippenberg D, van Knippenberg B, Monden L and de Lima F (2002) Organizational identification after a merger: A social identity perspective. British Journal of Social Psychology, 41(2): 233-252.

van Leeuwen E, van Knippenberg D and Ellemers N (2003) Continuing and changing group identities: The effects of merging on social identification and ingroup bias. Personality and Social Psychology Bulletin, 29(6): 679-690. 
${ }^{1}$ The study also included preliminary analyses that controlled for demographic variables (i.e., age, gender, years of employment). The demographics explained only .4 percent of the variance in post-merger identification, $F_{\text {change }}=.17, p=.92$, and .8 in the variance of uncertainty, $F_{\text {change }}=.37, \mathrm{p}=.78$. Thus, the results of the analyses were not significantly affected through the inclusion of the demographics as covariates. Therefore, statistical analyses are reported without demographic variables, increasing statistical power for all reported analyses.

${ }^{2}$ The study also included a one-factorial ANOVA on the measure of post-merger identification. Organizational background predicted significantly the degree of post-merger identification, $F(1,136)=4.34, p=.006, \eta_{\mathrm{p}}{ }^{2}=.09$. Members of the high-status pre-merger organization identified more strongly with the post-merger organization $(M=3.72, S D=.70)$ than members of the other three organizations (organization $\mathrm{B}: M=3.37, S D=.92$; organization $\mathrm{C}: M=3.21, S D=.68$; organization $\mathrm{D}: M=3.32, S D=.56)$. This finding is in line with former research on organizational mergers and acquisitions (van Knippenberg et al., 2002; Terry, 2001).

${ }^{3}$ The study also included a one-factorial ANOVA on the measure of uncertainty. Organizational background predicted significantly the degree of uncertainty, $F(1,136)=3.80, p$ $=.01, \eta_{\mathrm{p}}{ }^{2}=.08$. Members of the high status pre-merger organization felt less uncertain $(M=2.03$, $S D=.65$ ) than members of the other three organizations (organization $\mathrm{B}: M=2.61, S D=.82$; organization C: $M=2.41, S D=.77$; organization $\mathrm{D}: M=2.47, S D=.77$ ). 
Continuity and Necessity 30

Table 1. Means, Standard Deviations, Cronbach's alpha (in Correlation Matrix Diagonal) and Correlations of the Dependent Variables

\begin{tabular}{lcccccc}
\hline & $M$ & $S D$ & $(1)$ & $(2)$ & $(3)$ & $(4)$ \\
\hline (1) Necessity & 2.64 & .89 & $(.60)$ & & & \\
(2) Sense of Continuity & 2.73 & .86 & $.18 *$ & $(.76)$ & & \\
(4) Post-merger Identification & 3.41 & .72 & $.29 * * *$ & $.51 * * *$ & $(.86)$ & \\
(5) Uncertainty & 2.31 & .79 & -.09 & $-.31 * * *$ & $-.40 * * *$ & (.72) \\
\hline$* p<.05 ; * * p<.01 ; * * * p<.001$ & & & & & &
\end{tabular}


Table 2. Summary of Regression Analysis for Necessity and Sense of Continuity Predicting Postmerger Identification and Uncertainty

\begin{tabular}{|c|c|c|c|c|c|c|}
\hline & \multicolumn{3}{|c|}{ Post-merger Identification } & \multicolumn{3}{|c|}{ Uncertainty } \\
\hline & $B$ & $S E B$ & $\beta$ & $B$ & $S E B$ & $\beta$ \\
\hline \multicolumn{7}{|l|}{ Step 1} \\
\hline \multicolumn{7}{|c|}{ Organization (dummy coded) } \\
\hline Dummy 1 & -.35 & .20 & -.16 & .58 & .21 & $.26 * *$ \\
\hline Dummy 2 & -.51 & .15 & $-.34 * *$ & .38 & .16 & $.24 *$ \\
\hline Dummy 3 & -.39 & .17 & $-.23 *$ & .45 & .18 & $.24 *$ \\
\hline$\Delta R^{2}$ & .09 & & & .08 & & \\
\hline$\Delta F$ & 4.34 & & & 3.80 & & \\
\hline \multicolumn{7}{|l|}{ Step 2} \\
\hline Necessity & .18 & .06 & $.22 * *$ & -.02 & .07 & -.03 \\
\hline Continuity & .38 & .07 & $.45 * * *$ & -.21 & .08 & $-.23 *$ \\
\hline$\Delta R^{2}$ & .24 & & & .05 & & \\
\hline$\Delta F$ & $23.7^{7}$ & & & 3.55 & & \\
\hline \multicolumn{7}{|l|}{ Step 3} \\
\hline \multicolumn{7}{|l|}{ Necessity $\mathrm{x}$} \\
\hline Continuity & -.15 & .06 & $-.17 *$ & .16 & .08 & $.18 *$ \\
\hline$\Delta R^{2}$ & .03 & & & .03 & & \\
\hline$\Delta F$ & $5.05^{\circ}$ & & & 4.36 & & \\
\hline
\end{tabular}

Note. $* p<.05 ; * * p<.01 ; * * * p<.001$; Predictors were centralized (Aiken \& West, 1991). 
Table 3. Summary of Regression Analysis for Status, Necessity and Sense of Continuity Predicting Post-merger Identification and Uncertainty

\begin{tabular}{|c|c|c|c|c|c|c|}
\hline & \multicolumn{3}{|c|}{ Post-merger Identification } & \multicolumn{3}{|c|}{ Uncertainty } \\
\hline & $B$ & $S E B$ & $\beta$ & $B$ & $S E B$ & $\beta$ \\
\hline \multicolumn{7}{|l|}{ Step 1} \\
\hline Status $(0=$ low, $1=$ high $)$ & .12 & .12 & .08 & -.27 & .15 & -.17 \\
\hline Necessity & .17 &. .06 & $.20 * *$ & -.03 & .07 & -.03 \\
\hline Sense of Continuity & .38 & .07 & $.45 * * *$ & -.21 & .08 & $.23 *$ \\
\hline$\Delta R^{2}$ & .31 & & & .12 & & \\
\hline$\Delta F$ & 20.3 & $* *$ & & 6.12 & & \\
\hline \multicolumn{7}{|l|}{ Step 2} \\
\hline Status x Necessity & .23 & .14 & .38 & -.15 & .17 & -.23 \\
\hline Status x Continuity & -.02 & .14 & -.14 & .10 & .16 & .16 \\
\hline Necessity x Continuity & -.18 & .07 & $-.20 *$ & .18 & .08 & $.20 *$ \\
\hline$\Delta R^{2}$ & .04 & & & .04 & & \\
\hline$\Delta F$ & 2.48 & & & 1.81 & & \\
\hline \multicolumn{7}{|l|}{ Step 3} \\
\hline \multicolumn{7}{|l|}{ Necessity x Continuity $\mathrm{x}$} \\
\hline Status & -.05 & .14 & -.08 & -.07 & .17 & -.11 \\
\hline$\Delta R^{2}$ & .001 & & & .001 & & \\
\hline$\Delta F$ & .13 & & & .18 & & \\
\hline
\end{tabular}

Note. $* p<.05 ; * * p<.01 ; * * * p<.001$; Predictors were centralized (Aiken \& West, 1991). 
Table 4. Results for the Moderated Path Analysis Approach

\begin{tabular}{llcccc}
\hline & \multicolumn{1}{c}{$X$} & & & \\
& & & & \\
& Necessity & Uncertainty & Continuity & $X Z$ & $R^{2}$ \\
\hline Uncertainty & .02 & & $0.21^{* *}$ & $.16^{*}$ & $.15^{*}$ \\
Post-merger & & & & \\
Identification & $-.21 * *$ & $-.32 * *$ & & $.27 * *$ \\
& & & & \\
\hline
\end{tabular}

Note. Entries in columns $X, M, Z$, and $X Z$ are unstandardized regression coefficients. The first row reflects the regression equation for $\mathrm{M}$ (i.e., the mediator). The second row reflects the regression equation for Y (i.e., the dependent variable). Empty cells reflect that the associated variables are not part of the respective regression equation. Further, in all regression equations, the study controlled for participants' organizational background (dummy coded). These dummy variables are not reported here. The equations reflect the First Stage Moderation Model (Edwards and Lambert, 2007)

$* p<.05, * * p<.01$ 
Table 5. Analysis of Simple Effects Moderation by Sense of Continuity (First Stage Moderation Model)

\begin{tabular}{|c|c|c|c|c|c|}
\hline \multirow{2}{*}{$\begin{array}{c}\text { Moderator } \\
\text { variable }\end{array}$} & \multicolumn{2}{|c|}{ Stage } & & \multicolumn{2}{|c|}{ Effect } \\
\hline & First & Second & Direct & Indirect & Total \\
\hline \multicolumn{6}{|l|}{ Sense of continuity } \\
\hline Low & $-.13^{\dagger}$ & $-.32 * *$ & $.21 * *$ & $.04^{\dagger}$ & $.25 * *$ \\
\hline High & .16 & $-.32 * *$ & $.21 * *$ & .05 & $.16^{*}$ \\
\hline Differences & $.29 *$ & - & - & $-.09 *$ & $-.09 *$ \\
\hline
\end{tabular}

Note. Entries are unstandardized regression coefficients. For rows labeled low and high, table entries are simple effects computed using coefficient estimates from Table 3. Differences in simple effects were computed by subtracting the effects for low continuity from the effects for high continuity. Tests of differences for the first stage are equivalent to tests of perceived necessity by sense of continuity on uncertainty, as reported in Table 3. The indirect effect equals the product of the first and second stages. The second stage is equal in both conditions in this model. Effects involving products of coefficients (indirect effect, total effect) were tested using bias-corrected confidence intervals derived from bootstrap estimates. The second stage effect and the direct effect are identical for low and high continuity in this model.

${ }^{\dagger} p<.05$, (one sided), $* p<.05, * * p<.01$. 
Continuity and Necessity 35

Figure 1

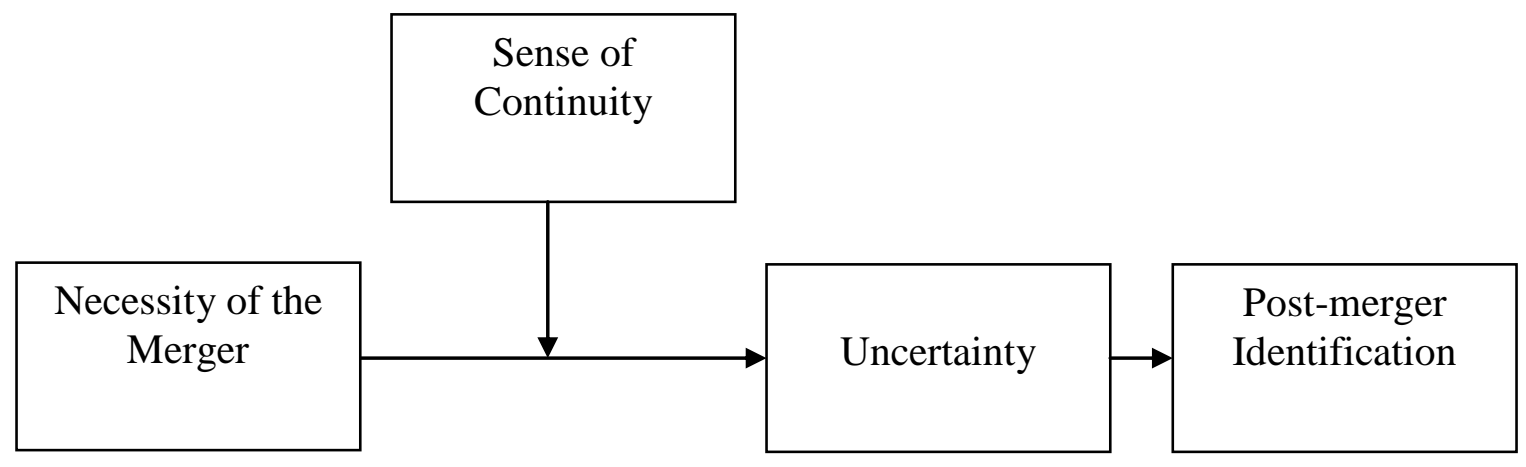


Figure 2. Post-merger identification and uncertainty as a function of sense of continuity and necessity of the merger.
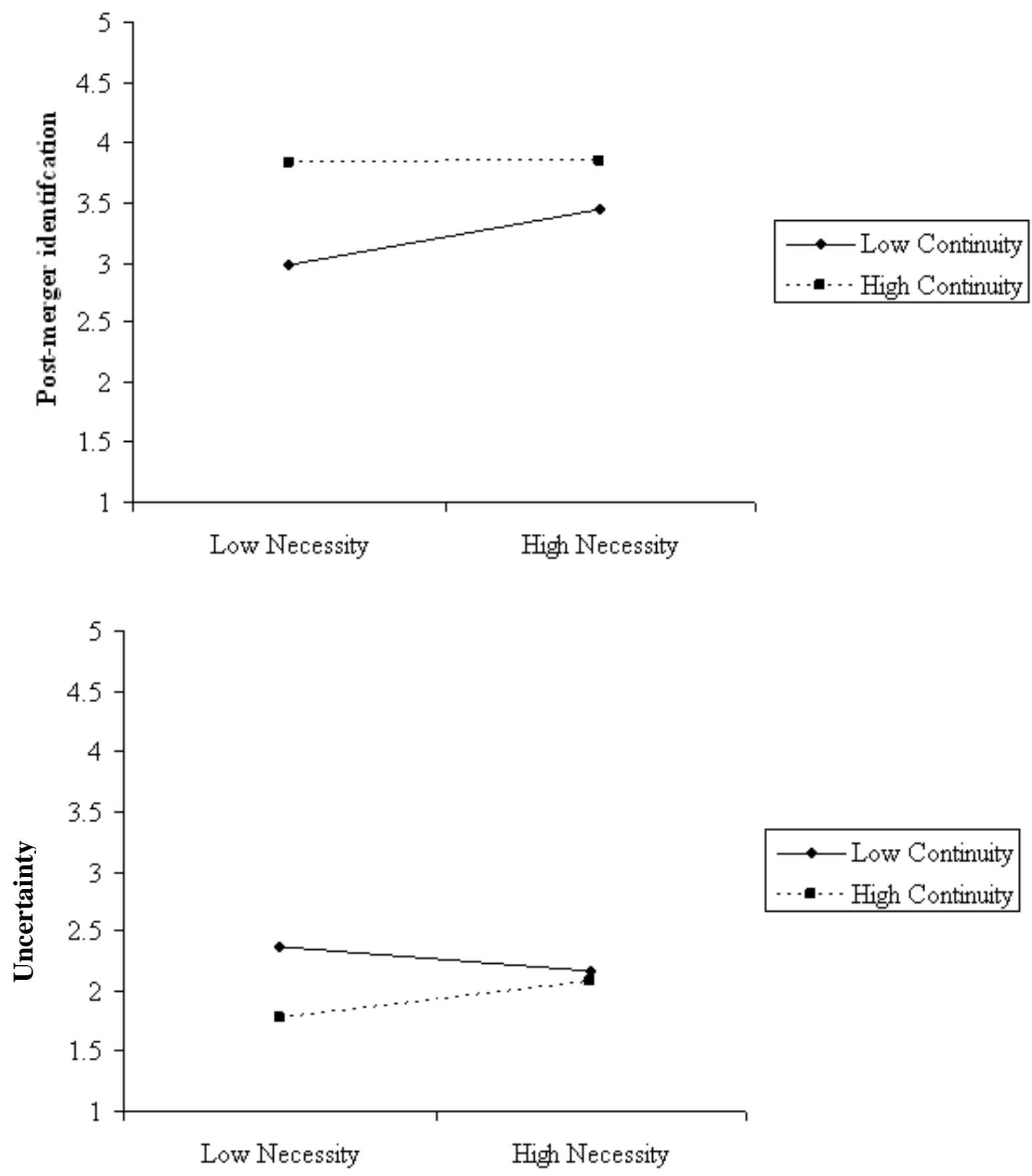


\section{Appendix}

\section{Necessity of the merger}

I think the merger has been necessary for the preservation of my former organisation.

I think the integration has been necessary to support the growth (i.e., better conditions, more resources, etc.) of my former organisation.

\section{Uncertainty}

During the integration I have felt generally uncertain.

During the integration I have felt threatened about losing my job.

During the merger I have been concerned that I will lose important financial benefits.

During the merger I have not felt safe with regards to my future career.

\section{Sense of continuity}

In the new organisation the identity of the former organisation is still visible.

The new organisation is very similar to my former organisation I worked for.

My new organisation is very representative for my former organisation.

\section{Post-merger Identification}

I identify myself with the new organisation.

I consider myself as belonging to the new organisation.

I feel strong ties with the new organisation. 